\section{Cartoon Editorial}

Check for updates

\section{OPEN ACCESS}

Received: Dec 2, 2019

Accepted: Dec 17, 2019

Address for Correspondence:

Min Suk Chung, MD, PhD

Department of Anatomy, Ajou University

School of Medicine, 164 World Cup-ro,

Yeongtong-gu, Suwon 16499,

Republic of Korea.

E-mail: dissect@ajou.ac.kr

c 2019 The Korean Academy of Medical

Sciences.

This is an Open Access article distributed under the terms of the Creative Commons Attribution Non-Commercial License (https:// creativecommons.org/licenses/by-nc/4.0/) which permits unrestricted non-commercial use, distribution, and reproduction in any medium, provided the original work is properly cited.

ORCID iD

Min Suk Chung (iD

https://orcid.org/0000-0002-0527-9763

\section{Disclosure}

The author has no potential conflicts of interest to disclose.

\title{
Advancement Comes with Responsibility
}

\author{
Min Suk Chung (D)
}

Department of Anatomy, Ajou University School of Medicine, Suwon, Korea

- See the article "Venous Thromboembolism in Children and Young Adults in Korea: Analysis of the Korean Health Insurance Review and Assessment Service Database" in volume 34, number 49, e316.

\section{(D)}

Advancement comes with responsibility.

Incidence of the venous thromboembolism (VTE) in infancy has increased.

per 100,000

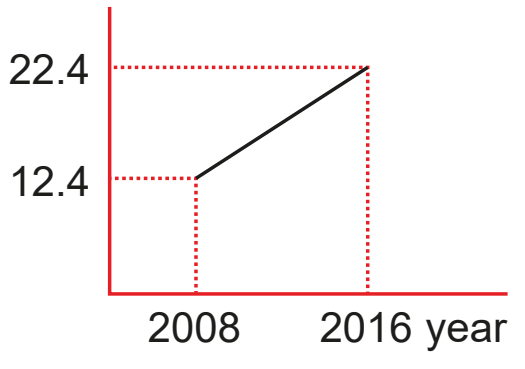

\section{Advanced medical tech-} nology also means more umbilical catheterization,

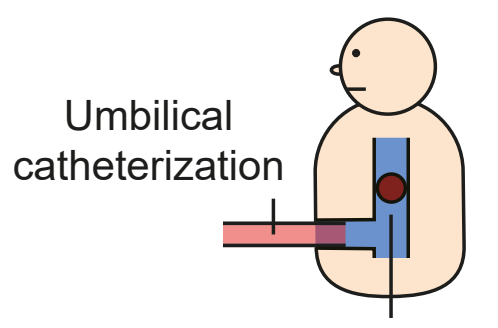

Portal vein

which results in

VTE of the portal vein.
It is because of advanced medical technology to detect VTE that was previously undiagnosed.

VTE
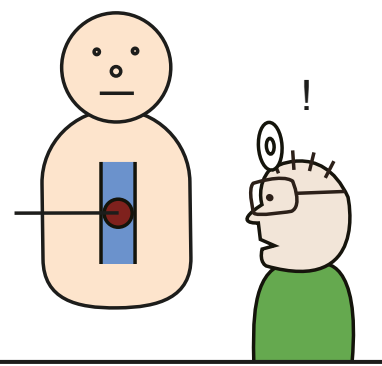

The advanced medical technology gives rise to need of more careful concern for patients.

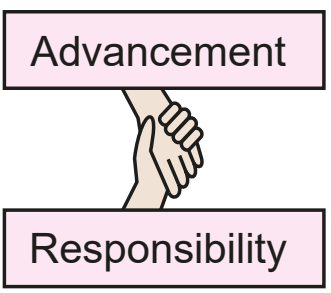

Advancement must come with responsibility. 